This Section of Epidemiology and Psychiatric Sciences appears in each issue of the Journal and is dedicated to all forms of creative production born of an intimate and individual urge, often secretive, unbound from the conventional art system rules. Through short descriptions of the Outsider art work of prominent artists and new protagonists often hosted in community mental health services, this Section intends to investigate the latest developments of the contemporary art scene, where the distances between the edge and the centre are becoming more and more vague.

Carole Tansella, Section Editor

\title{
Ken Grimes: alien communications
}

\author{
C. Russell \\ English and American Studies, Rutgers University, Newark, New Jersey, USA
}

Received 26 March 2018; Accepted 5 April 2018

Key words: Outsider art, popular culture, alien contact, aesthetic reception.

Ken Grimes (b. 1947) has long been captivated by the concept of life existing in other parts of the universe - and by the possibility that aliens may have had and even still exert an influence on the thoughts and actions of humans here on Earth. In this, he is not unique. Grimes falls squarely within a wide-spread popular culture fascination with the possibility that we are not alone. Recent studies have found that nearly half of Americans believe in extraterrestrial life and that one-third are convinced that extraterrestrial beings have visited the Earth. The paintings of Ken Grimes address these themes and posit that humans may have had a long history of contact with outer-space creatures.

Ken Grimes is an artist, and he can be considered an Outsider artist. While he is familiar with the Western art tradition, studied art during a very brief college enrolment, is represented by Ricco/Maresca, a major New York gallery, and is proud to receive international recognition for his work, he pursues art not with the intent of participating in art history, but from a deep personal need, a need that at times interferes significantly with the management of daily life,

Address for correspondence: C. Russell, 312 Sam Spear Road, Westport, New York, 12993, USA.

(E-mail: crr@scarletmail.rutgers.edu) yet one that finds fulfilment in the creative process and the responses it has generated.

As with much Outsider art, Grimes' work both testifies to and is a way of coping with the passions of a mind that finds itself pushing beyond the perceptual and behavioural bonds within which the majority of us - his audience - exist. Ken Grimes is fortunate he has his art; he is fortunate to be able to live and work within Fellowship House, a residential community mental health program in New Haven, Connecticut that encourages intuitive artistic creativity, and he is fortunate to have found an audience that responds to his work. For in his creative drive and within his viewers' reception lie so much of the mystery and power of Outsider art.

Since the mid-1980s, Grimes has used to his art to document, depict and convey his discoveries and speculations about the space-related subjects that have intrigued him. His paintings are dramatic. Working almost exclusively in black and white acrylic paint on canvas or wood, or in black ink on white paper, Grimes presents bold, sparsely drawn symbols and texts (Russell, 2005). His paintings illustrate and describe mysterious occurrences, troubling questions, or speculative arguments about extraterrestrial phenomena that have become part of the public discourse or that the artist has investigated on his own. Very often, a Grimes painting may consist primarily or even entirely of a text rendered in his signature white 


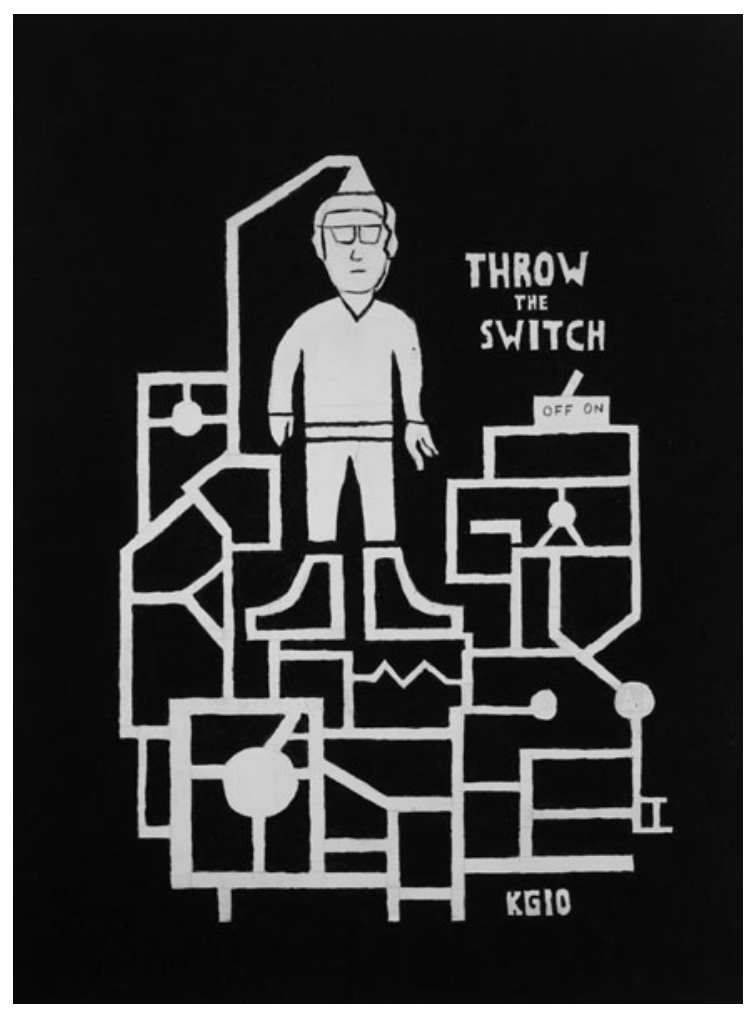

Fig. 1. Ken Grimes Untitled, (Throw the Switch) 2010 Acrylic on masonite $48 \times 36$ in. $(121.9 \times 91.4 \mathrm{~cm})$.

block letters. Typically, such a work might describe unusual, space-related phenomena, summarise narratives about strange incidents, or detail myriad bits of arcane data in the conviction that he - and perhaps, he wonders, only he - might be able to identify significant patterns and reveal elusive meanings in the collective record and in his personal experience that proves space-alien contact with Earth.

Grimes is driven to create through a sincere - and determined - belief in a possibly imminent confirmation of signs of a cosmic connection with Earth, and by his confidence that art can be an agent of revelation. Indeed, his paintings reveal a passion that may be close to religious inspiration, making his works something other than aesthetic exercises or mere obsessive, personal rants. It is an art that makes demands, that directly addresses its audience. Like that of many visionary artists, Grimes' work does not envision a removed, merely aesthetic reception. Rather, they simultaneously make a personal statement and directly challenge their viewers, demanding a reaction. If they exhibit an isolate's unguarded psychological openness buttressed by the bold conviction of impassioned vision, they seek to engender a collaborative and affirmative - response from the viewer.

Indeed, the glory of strong art, including Outsider art, is that the individual artist might go on the most

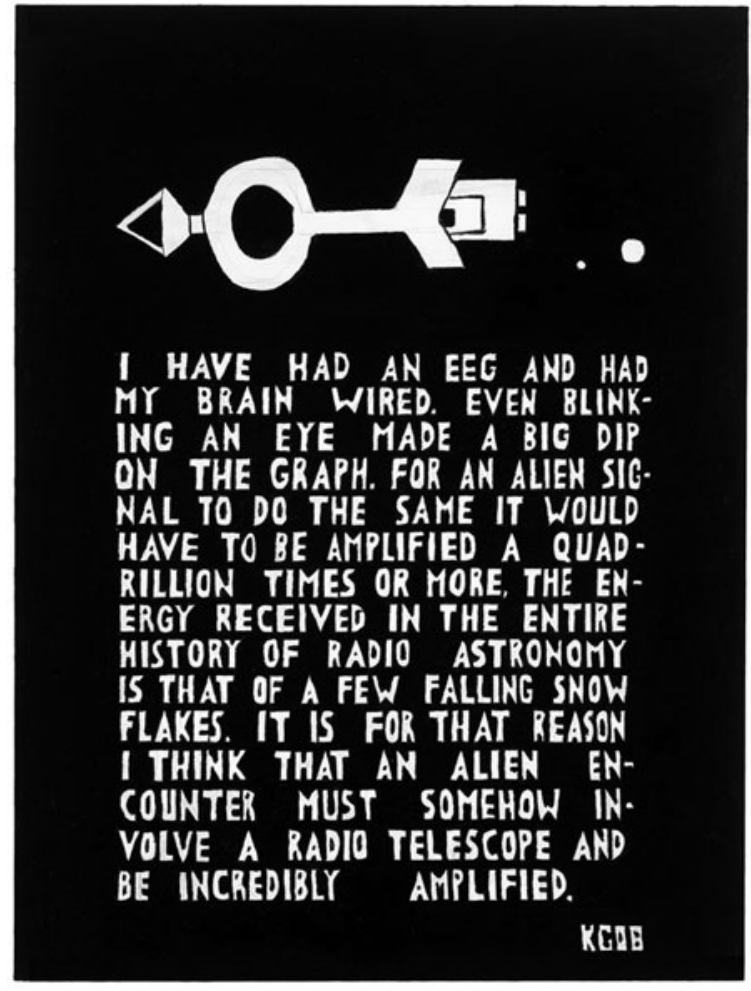

Fig. 2. Ken Grimes I Have Had an EEG 2008 Acrylic on masonite $48 \times 36$ in. $(121.9 \times 91.4 \mathrm{~cm})$.

private journey into the self to confront the inner demons that challenge the integrity of self, yet be able to recover meaning or find a way of dealing with those demons. The audience experiences the results of this behaviour and is stirred to recognise their own inner echoes that they might not have the drive or courage to engage. The great mystery, even paradox of art is that the most private experience can be the most universal.

And, even more, the astonishing power of Outsider art is also evident when the artist - as in the case of Ken Grimes - in the process of confronting inner demons seizes upon, and envisions anew, the demons of doubt, fear and wonder that are abroad in mass culture. And then we might recognise, perhaps somewhat nervously, all around us a collective obsession within our culture that many of our compatriots consider plausible reality. At this point, we may be led to rethink our approach to Outsider art and ask what it means when the intuitive vision of one artist illuminates the concerns of millions.

\section{Reference}

Russell C (2005). The truth in black and white: the art of ken grimes Raw Vision 50, 26-31. 
About the author:

Charles Russell is Professor Emeritus of English and American Studies at Rutgers University, Newark, where he was Director of American Studies. Among the books, he has published are Groundwaters: A Century of Art by Self-Taught and Outsider Artists
(2011); Self-Taught Art: The Culture and Aesthetics of American Vernacular Art (2001); Poets, Prophets, and Revolutionaries: The Literary Avant-Garde from Rimbaud through Postmodernism (1985).

Carole Tansella, Section Editor. 